\title{
Menstrual Smear can be Used to Screen for Endometrial Pathology
}

\author{
Petrikovsky BM* \\ Professor and former Chairman of Obstetrics and Gynecology, Nassau University Medical Center, USA
}

*Corresponding author: Petrikovsky BM, Professor and former Chairman of Obstetrics and Gynecology, Nassau University Medical Center, USA.
Received Date: September 25, 2019

Published Date: October 03, 2019

\section{Introduction}

It is well-known, that the PAP smear in its various modifications is currently the gold standard of cervical cancer prevention and treatment worldwide [1-3]. It is less well-known, however, that the original paper by Traut and Papanicolaou was entitled, "Cancer of the uterus: The vaginal smear in its diagnosis" [4]. The pioneering research was first presented at the section on obstetrics and gynecology at the seventy-second Annual Session of the California Medical Association (Los Angeles, May 2-3, 1943). In 1943, Traut and Papanicolaou wrote the following:

"The malignant epithelial cells exfoliate from the surface of neoplastic growths, much as do normal cells. They then float downward into the vaginal fornix, where they accumulate and become mixed with normal cells of epithelial and blood origin, as well as with mucus and cellular debris. The rate of exfoliation of the malignant cells seems to be dependent upon the rate of growth of the neoplasm and its size" [4].

Since up to fifteen percent of uterine cancers are detected in premenopausal women, we suggested a new endometrial cancer screening test based on the endometrial cell's evaluation. The endometrial cells were obtained from the menstrual content of menstrual pads, cups, and intravaginal tampons.

\section{Material and Methods}

Fourteen hundred menstrual pads, cups, and tampons were evaluated for the presence of identifiable endometrial cells on the 2nd, 3rd, and last days of the menstrual cycle. The initial assessment was performed using standard PAP smear technology. Later in the study, a thin PAP smear technique was added to the methodology. The cells were collected, spun and placed onto slides. Finally, a cell retrieval and a suspension technique were used.

\section{Results}

All 1400 specimens were evaluated. Based on the quality of the specimens, the results were subdivided into four main groups:

1. Group I: Unsatisfactory for evaluation due to the extensive presence of red blood cells, artifacts and debris, etc. - 104 (7.4\%)

2. Group II: Satisfactory for evaluation but with limited interpretation value due to some obscuring blood, inflammation, cytolysis, etc. - 98 (7\%)

3. Group III: Satisfactory for evaluation with limited interpretation - 518 (41\%)

4. Group IV: Satisfactory for evaluation and interpretation $680(49 \%)$

A normal menstrual pattern was identified in 1353 cases, endometrial hyperplasia was suspected in 46 cases, and one case was suspicious for invasive disease (96\%).

The patients with suspicious results consented to further evaluation which included sampling with endometrial biopsy (18) and D\&C (29).

31 patients were confirmed to have endometrial hyperplasia. Endometrial cancer was detected in two cases.

\section{Discussion}

Endometrial cancer is one of the few malignancies growing in incidence and mortality in the United States [5]. It is the fourth most common cancer diagnosed and the seventh most common cause of cancer deaths among U.S. women [6]. Up to $30 \%$ of patients with endometrial cancer are younger than 54 years, and $9 \%$ of women 
in whom the disease is diagnosed are younger than 44 years [57]. Although the assumption is that premenopausal women would have early-stage, low-grade malignancies, this may not be the case. In a population-based registry (Geneva Cancer Registry), 3.2\% of women with endometrial cancer were 45 years old or younger, and only $18 \%$ of these women had stage IA, grade 1 endometrial cancer [8].

In 2000, we presented our preliminary results using menstrual content to screen for endometrial cancer in high-risk younger women [9]. We concluded that menstrual smears do have diagnostic potential for endometrial cancer screening in a high-risk population. Although endometrial histology remains the gold standard, cytology may be helpful for screening purposes. Smith, et al [10] studied 60 patients, five of whom had endometrial hyperplasia and two of whom had cancer. Cytology was successful in identifying four out of the seven cases. The sensitivity of the endometrial cytology for detecting hyperplasia/carcinoma was $57 \%$ and the specificity was 98\% [9]. Although the accuracy of our approach has yet to be established, it may be similar to the guaiac method for colorectal screening. Guaiac populations screening was credited with reducing the mortality associated with colon cancer by about $25 \%$ [11]. Recently, several colon cancer screening guidelines have recommended replacing older, low-sensitivity, guaiac-based occult blood testing with either newer high-sensitivity guaiac-based occult blood screening or immunochemical testing [12].

\section{Conclusion}

Cytologic evaluation of the blood obtained from menstrual pads, cups, and tampons is a feasible noninvasive screening tool for endometrial pathology. Further studies are needed to determine the sensitivity and the specificity of the test, possibly improving both by adding molecular markers to the cytologic evaluation of the specimens.

\section{Acknowledgement}

None.

\section{Conflict of Interest}

Authors declare no conflict of interest.

\section{References}

1. Zhao C, Florea A, Onisko A, Austin RM (2009) Histological follow-up results in 662 patients with Pap test findings of atypical glandular cells: results from a large academic womens hospital laboratory employing sensitive screening methods. Gynecol Oncol 114(3): 383-389.

2. (2012) American College of Obstetricians and Gynecologists (ACOG) Practice Bulletin no. 128: Diagnosis of abnormal uterine bleeding in reproductive-aged women. Washington, USA.

3. Traut HF, Papanicolaou GN (1943) Cancer of the uterus: the vaginal smear in its diagnosis. Am J Obstet Gynecol 59(2): 121-122.

4. Cronin KA, Lake AJ, Scott S, Sherman RL, Noone AM, et al. (2018) Annual report to the nation on the status of cancer, part I: national statistics. Cancer 124(13): 2785-2800.

5. Shah MM, Wright JD (2011) Management of endometrial cancer in young women. Clin Obstet Gynecol 54(2): 219-225.

6. Erkanli S, Ayhan A (2010) Fertility-sparing therapy in young women with endometrial cancer: 2010 update. Int J Gynecol Cancer 20(7): 1170-1187.

7. Evans-Metcalf ER, Brooks SE, Reale FR, Baker SP (1998) Profile of women 45 years of age and younger with endometrial cancer. Obstet Gynecol 91(3): 349-354.

8. Navarria I, Usel M, Rapiti E, Neyroud-Caspar I, Pelte MF, et al. (2009) Young patients with endometrial cancer: how many could be eligible for fertility-sparing treatment? Gynecol Oncol 114(3): 448-451.

9. Petrikovsky BM (2000) PET smear: Will it ever work? NCMC Proceedings 6: 22-26.

10. Smith RA, Breitkopf DM, Wong JY, Logrono R (2000) Comparison of endometrial cytology to endometrial histology in the detection of hyperplasia and carcinoma. Obstet Gynecol 95(4 Suppl 1): S28.

11. Bretthauer M (2000) Evidence for colorectal cancer screening. Best Pract Res Clin Anaesthesiol 24(4): 417-25.

12. Levin B, Lieberman DA, McFarland B, Smith RA, Brooks D, et al. (2008) Screening and surveillance for the early detection of colorectal cancer and adenomatous polyps: a joint guideline from the American Cancer Society, the US Multi-Society Task Force on colorectal cancer, and the American College of Radiology. CA Cancer J Clin 58(3): 130-60. 